\title{
Effect of experimental wet and dry cycles on bamboo fibre reinforced acrylic polymer modified cement composites
}

https://doi.org/10.1515/jmbm-2020-0009

Received Apr 24, 2020; accepted Aug 17, 2020

Abstract: This study experimentally evaluated the effect of accelerated wet/dry cycles on the dimensional stability and some selected mechanical properties of polymer modified vegetable fibre cement composites. The bamboo fibres were pre-treated with $10 \%$ conc. of sodium hydroxide and varied from $0-2.0 \%$ while acrylic polymer admixture of $10 \% \mathrm{w} / \mathrm{w}$ of cement was added to improve the properties. The modified fibre-cement composites were subjected to 50 cycles of wet/dry processes to simulate natural weathering process of the environment. The samples were subjected to water absorption, thickness swelling, modulus of rupture (MOR) and modulus of elasticity (MOE) after 28 days of curing and aging cycles respectively using 5 replicates. One way ANOVA at $\mathrm{p}<0.05$ was used to analyse the results. Scanning electron microscope (SEM) and Fourier Transformer Infrared Spectroscopy (FTIR) analyses were conducted on the samples. The results showed improvement of 33.3, 64, 71 and 57\% in MOR and 135, 85, 101 and $188 \%$ in MOE for samples with $0.5,1,1.5$ and $2 \%$ fibre inclusion after ageing tests. Significantly improved dimensional stability values were observed in this study in comparison with data from similar ageing tests conducted on unmodified vegetable fibre-cement matrix. SEM micrographs showed marginal increase in the size of the pores before and after ageing tests. FTIR analysis indicated increase in intensities during the ageing tests especially for spectra bands located at $3384-3520 \mathrm{~cm}^{-1}$ which are denoted for $\mathrm{O}$ $\mathrm{H}$ vibration stretching as well as 1676,1726 and $1794 \mathrm{~cm}^{-1}$ which depict the presence of carbonyl groups because of absorption of polymers to the fibre surface during the ageing cycles. The study has shown that wet/dry ageing cycles

\footnotetext{
*Corresponding Author: Banjo A. Akinyemi: Structures and Building Materials Unit, Department of Agricultural and Biosystems Engineering, Landmark University, P.M.B. 1001 Omuaran, Kwara State, Nigeria; Email: bantonbows@gmail.com Temidayo E. Omoniyi: Department of Wood Products Engineering, University of Ibadan, Nigeria
}

showed less harmful effect on vegetable fibre cement composites provided the cement matrix is modified with polymer admixtures.

Keywords: natural fibres; weathering; improvement; properties; durability; modify

\section{Introduction}

Presently, the desire for renewable, eco-friendly and less energy consuming building materials has fuelled the research on unconventional materials as a substitute for some construction applications. The use of natural or cellulose fibre has been identified as a good material based on its availability, renewability, non-carbon emission signature, biodegradability and attractive physico-mechanical properties among others. Regardless of these merits, its adoption for industrial applications most especially as fiber reinforced cement composites is hampered by durability issues after a prolonged period of exposure in the environment. This challenge is closely linked to fibre mineralization, increase and decrease in fibre fracture and pullout due to alkali attack as well as variations in pores caused by high moisture absorption rate $[1,2]$. These factors consequently affect the toughness and post-cracking strength, hence the overall engineering properties would be negatively influenced [3]. Previous studies have shown that fiber reinforced cement composite's degradation could be mitigated either through fibre modification or modification of the cement matrix [4]. Fiber modification techniques include impregnating/coating with water repellent [5]. Cement matrix modification could be achieved through use of supplementary cementitious materials such as pozollans and ashes [6]. While in another quarter, polymer chemical admixtures was utilised effectively to modify the cement composites with enhanced properties observed after some tests were performed [7]. Cement mortars modified with polymers tend to have improved adhesion between fibers and matrix coupled with reduced per-

ðOpen Access. ( 2020 B. A. Akinyemi and T. E. Omoniyi, published by De Gruyter. 
Table 1: Mix design

\begin{tabular}{cccccc}
\hline Components & X & A & Mix design & C & D \\
\hline Cement (\%) & 25 & 24.80 & 24.68 & 24.55 & 24.43 \\
Sand (\%) & 75 & 74.40 & 74.02 & 73.65 & 73.27 \\
Bamboo fibers (\%) & 0 & 0.5 & 1.0 & 1.5 & 2.0 \\
Polymer (\%) & 0 & 0.3 & 0.3 & 0.3 & 0.3 \\
*Water/cement & 0.40 & 0.40 & 0.40 & 0.42 & 0.46 \\
\hline
\end{tabular}

*Water/cement was expressed in ratio, others were expressed in $\%$

meability because of low porosity [8,9]. Such modified systems possess improved flexibility and crack-bridging potential because of their low elastic modulus [10]. Polymer modification encourages the cement composite to breathe while allowing water vapour permeability without exerting high pressure at the cement matrix interface which could lead to cracking [11]. However, the long term performance of this cellulose fiber reinforced modified cement composite is yet to be determined which prompted the need for this present study. On exposure of cementitious materials to the environment, physical and chemical factors cause microstructural alterations within the cement composite [12]. Physical attack mechanisms include erosion such as wet/dry environment, abrasion, cavitation reaction or freeze/thaw cycles. Most tropical environment are characterised by cycles of moisture and temperature variations which cause cement composite leaching leading to development of microcracks [13]. The results of these physical factors of thermal fluctuations on the composites include volume changes which encourage stress development within the microstructure, hence micro-cracking in the cement material increases [14]. On the other hand, the chemical mechanism responsible for degradation during these cycles is air which is made up of carbon dioxide. This in combination with moisture produces a carbonation effect and subsequent deposition of calcium carbonate in the composite's microstructure [14]. This condition offers both positive and negative influence on the cement composite properties. On one hand, it causes reduction in pores because it occupied more volume than the calcium hydroxide that was replaced while the water given up by $\mathrm{Ca}(\mathrm{OH})_{2}$ during this phase helps cement hydration hence improved strength. But on the other hand, changes in volume are induced by the carbonation process which leads to shrinkage induced cracking. These effects which take place during long term wet/dry cycles have significant impact on the durability and properties of natural fibre reinforced cement composites. This present study aims to evaluate the durability of bamboo fibers used as reinforcement in polymer modified cement composition through assessment of the dimensional stability, mechanical properties, microstructural and chemical compositions after subjecting them to experimental ageing cycles.

\section{Materials and methods}

The bamboo fibers used in this experiment were from culms (Bambusa vulgaris species) obtained in Landmark University. These were dried at $30^{\circ} \mathrm{C}$ for two weeks and later milled to $2.00 \mathrm{~mm}$ sizes. The fibers were pre-treated with sodium hydroxide ( $10 \%$ conc.) and thereafter washed several times to allow leaching of the chemicals and other extractives of the cellulose plant. The fibers were allowed to dry naturally in the laboratory at $24^{\circ} \mathrm{C}$ for two weeks before it was stored in polythene nylon before usage. Acrylic polymer admixture containing $50 \%$ solid polymer content, $\mathrm{pH}$ of 9.2 and viscosity of $38-159 \mathrm{mPa} \cdot \mathrm{s}$ was used to modify the cement matrix with a view to enhance the mechanical properties of the fibre-cement composites. Type 1 Portland cement with $42.5 \mathrm{R}$ grading was used as the binder while $3 \%$ calcium chloride chemical was utilised as a cement accelerator in the composite. A cement: sand ratio of 1:3 and water/cement ratio of 0.48 were used in the mixing of the composites. The bamboo fibers were varied at $0,0.5,1.0$, 1.5 and $2.0 \%$ of the total weight of the constituents (see Table 1). A constant value of $10 \%$ acrylic polymer content was used based on previous studies which established this value as adequate to enhance the properties of the cement composite $[15,16]$.

\subsection{Sample preparation}

The accelerated ageing test was performed to evaluate the durability of the bamboo reinforced acrylic polymer modified cement composites when subjected to cycles of wetting and drying thereby imitating the natural process of 
ageing. To assess the composites reaction to this test, four formulations were used by varying the bamboo fibres at $0.5,1.0,1.5$ and $2.0 \%$ while keeping the acrylic polymer constant at $10 \%$ mass of cement based on previously obtained results. The desired quantities of sand and cement were mixed manually for three minutes, varied fibre contents based on mix design were added and blended together with the other constituents. Thereafter the desired constant amount of polymer was diluted with water from the water/cement ratio prior to its inclusion in the matrix. The slurry formed was placed in $5 \times 300 \times 400 \mathrm{~mm}$ moulds to cure naturally for 24 hours at $23{ }^{\circ} \mathrm{C}$ before demoulding. The test samples of $5 \times 50 \times 120 \mathrm{~mm}$ were cut and cured in water for 28 days and thereafter tested for modulus of elasticity (MOE) and modulus of rupture (MOR) using 5 replicates. The test was performed in accordance with EN 494 standard [17] by using 50 cycles of wet and dry procedure. The samples were immersed in $20^{\circ} \mathrm{C} \pm 5^{\circ} \mathrm{C}$ water for 18 hours and then placed in a ventilated oven at a temperature of $60^{\circ} \mathrm{C} \pm 5^{\circ} \mathrm{C}$ for 6 hours. A complete cycle involves both wet and dry procedure. After the completion of the test, another round of MOE and MOR tests were performed and the obtained results analysed.

\section{Results and discussion}

\subsection{Accelerated ageing effects on mechanical properties}

After 50 cycles of accelerated ageing, it was seen in Figures 1 and 2 that significant increment in MOR and MOE took place. Sample A after accelerated ageing test showed an improvement of $33.3 \%$ in MOR and $135 \%$ in MOE results. Sample B had an improvement of $64 \%$ in MOR and $85 \%$ in MOE, sample $\mathrm{C}$ increased by $71 \%$ in MOR values and $101 \%$ in MOE results and lastly sample D indicated significant improvement of $57 \%$ and $188 \%$ after accelerated ageing tests. The improvement in the mechanical strength could have been caused by the modification of the matrix by the acrylic polymer. These led to increase in fibre and matrix bonding because of intermingling of the cement hydrates and the polymer films. These products were able to block the development of voids and spaces leading to this improvement. Another reason as reported by Tonoli et.al., [18] who similarly observed an increase in strength after the ageing tests, was that improved densification and continuation of cement hydration during the ageing tests caused the properties of the composites to be improved. Tonoli et. al., [19] also remarked that MOR of fibre rein- forced cement composites increased significantly after 200 cycles of ageing tests due to the reduction of voids at the fibre matrix interface because of reprecipitation of cement hydration products into the voids. Soroushian et.al., [20] further confirmed this phenomenon in their studies by affirming that mineralization effect which is the precipitation of cement hydration products within the natural fibre center and at the densification at the interface caused the improved strength of natural fibre cement composites. In confirmation of the previous results observed, sample C with $1.5 \%$ bamboo fibre and $10 \%$ acrylic polymer content had the best performance for both the MOR and MOE results. It could be seen that beyond 1.5\% fibre inclusion, the values of the mechanical properties reduced; therefore the maximum fibre content should be maintained in order to produce a durable and structurally safe building component.

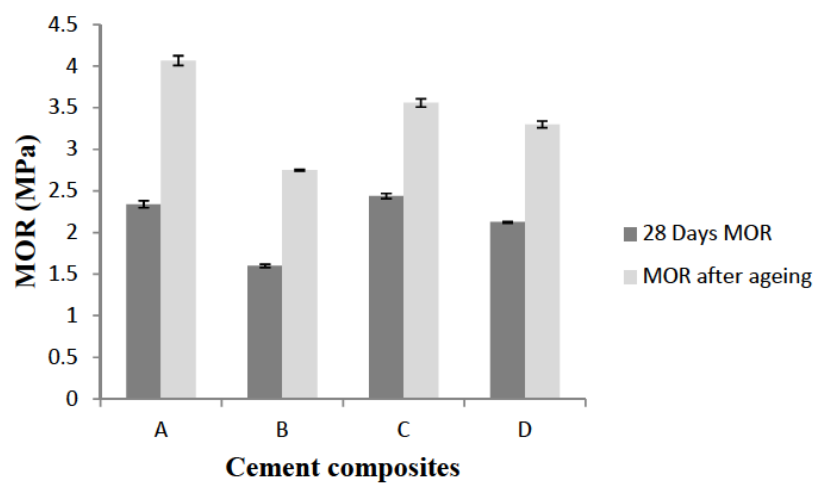

Figure 1: Accelerated ageing effects on MOR

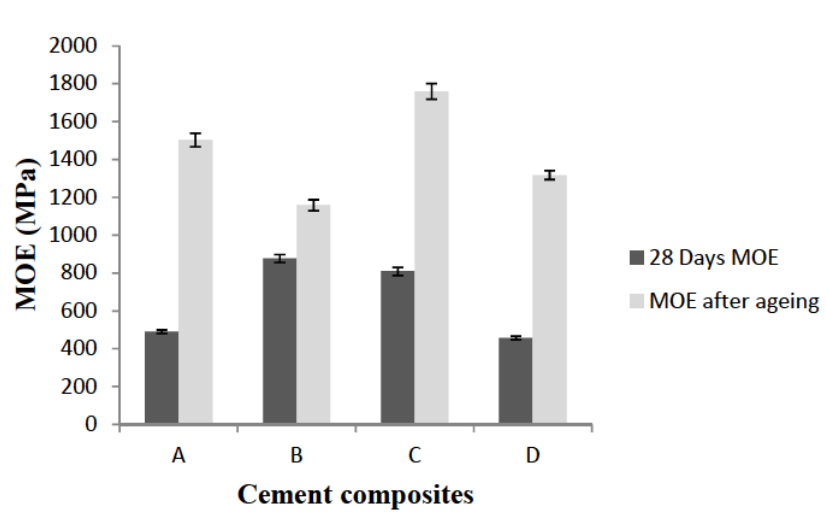

Figure 2: Accelerated ageing effects on MOE 


\subsection{Accelerated ageing effects on dimensional stability}

Figures 3 and 4 show the effects of accelerated ageing on the dimensional stability properties of the vegetable fibre modified cement composites. It was observed that as the fibres increased, there was increase in the water absorption and thickness swelling of the composites. Accelerated ageing tests had significant effects on the dimensional stability of the cement composites because of moisture migration into the cell walls and the interface. This led to irreversible cyclic swelling and drying of the cell walls which eventually affected the stability of the specimens especially the thickness swelling and water absorption. The polymer inclusion in the cement composites was able to an extent restrict the expected mass loss/increase of water as the polymer films acted as a coating on the pores by providing a barrier against the wet/dry cycles [21]. By so doing, it hinders water absorption and still permits evaporation because of its excellent water vapour permeability. In view of these actions, the water absorption and thickness swelling of this study were lesser in comparison with values obtained from other investigations involving accelerated ageing of cellulose fibre- unmodified cement composites. Tonoli et al., [22] recorded water absorption ranging from $10.5-20.5 \%$ when evaluating the effects of accelerated ageing cycles on properties of varied refined sisal pulp cement composites. Eucalyptus, coffee husk, banana pseudostem and coconut shell were studied as prospective fibre reinforcements in cement composites by Teixeira et al. [23]. Results of the wet/dry cycles showed water absorption of $6.41-11.45 \%$ with coffee husk and banana pseudostem having the least values.

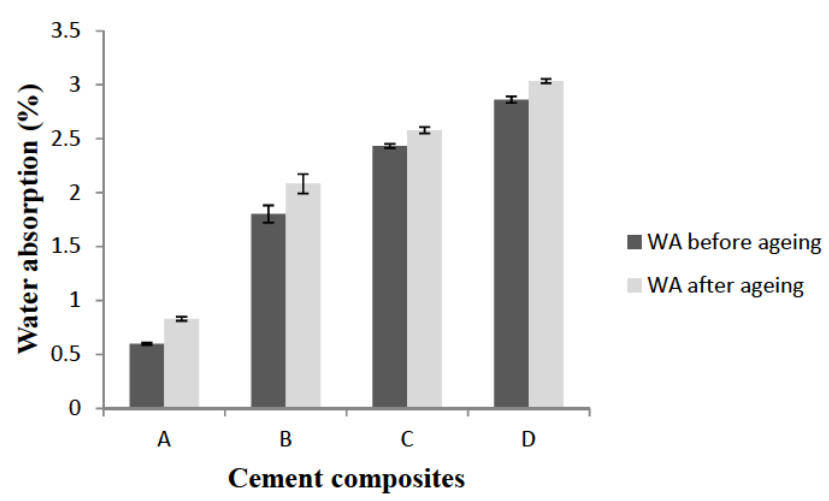

Figure 3: Accelerated ageing effects on water absorption

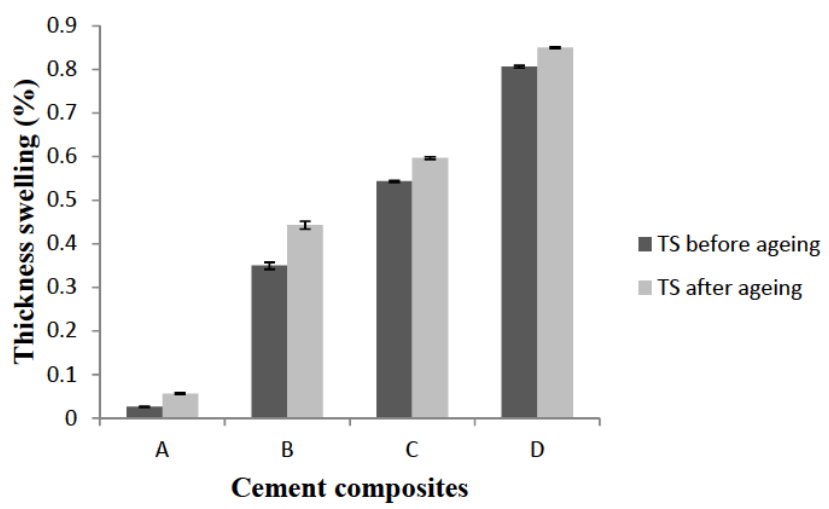

Figure 4: Accelerated ageing effects on water absorption

\subsection{Statistical analysis}

One way ANOVA of accelerated ageing effects on MOR, MOE, WA and TS showed significant values as shown in Table 2 and 3 . This possibly meant that degradation from the wet/dry cycles had low significant effect on the mechanical properties but had high significant effects on the dimensional stability properties of the fibre-polymer cement composites. It is also feasible that the residual stress due to processing of the cement composites had early release at the onset of the cycles thereby improving the resistance of the composites to bending stresses. As the immersion process was repeated, the water molecules were able to seep into the interface between the fibre and the matrix. This resulted into cyclic expansion and shrinkage with reduced load transfer efficiency from fibre to the matrix and hence the high significant effect of accelerated ageing on the dimensional stability properties.

\subsection{Scanning Electron Microscope (SEM) micrograph}

The micrograph in Figure 5(i) showed that the fibers were well embedded in the matrix with polymer films (whitish colour) covering the entire surface before ageing tests were performed. Also cement hydration and polymerisation products were equally dispersed between the fibrematrix interface on the images. However Figure 5(ii) indicates that after cyclic wetting/drying phases, the fibers expanded/shrank leaving obvious pores on the surface of the selected region. The fibers had possibly degraded slowly and mineralization of the cell walls had taken place due to concentrations of calcium hydroxide [24]. But, a look at the surface beyond the ridge showed a compact and smooth surface with minimal pores due to the addition of polymer admixture. The polymer films enhanced the energy 
Table 2: One way ANOVA of mechanical properties

\begin{tabular}{|c|c|c|c|c|c|c|}
\hline \multicolumn{7}{|c|}{ One way ANOVA of accelerated ageing effect on MOR } \\
\hline & Sum of Squares & $\begin{array}{l}\text { Degrees of } \\
\text { freedom }\end{array}$ & Mean Square & F-statistics & $\begin{array}{l}P \text { value } \\
(0.05)\end{array}$ & Inference \\
\hline Between groups & 3.7843 & 1 & 3.7843 & 8.4110 & 0.0199 & Sig. \\
\hline Within groups & 3.5994 & 8 & 0.4499 & & & \\
\hline Total & 7.3837 & 9 & & & & \\
\hline \multicolumn{7}{|c|}{ One way ANOVA of accelerated ageing effect on MOE } \\
\hline & Sum of Squares & $\begin{array}{l}\text { Degrees of } \\
\text { freedom }\end{array}$ & Mean Square & F-statistics & $\begin{array}{l}\text { P value } \\
(0.05)\end{array}$ & Inference \\
\hline Between groups & $1,549,508$ & 1 & $1,549,508$ & 26.9060 & 0.0008 & Sig. \\
\hline Within groups & 460,717 & 8 & 57,589 & & & \\
\hline Total & $2,010,225$ & 9 & & & & \\
\hline
\end{tabular}

Table 3: One way ANOVA of dimensional stability properties

\begin{tabular}{|c|c|c|c|c|c|c|}
\hline \multicolumn{7}{|c|}{ ANOVA of effect of accelerated ageing on water absorption } \\
\hline & Sum of Squares & $\begin{array}{l}\text { Degrees of } \\
\text { freedom }\end{array}$ & Mean Square & F-statistics & $\begin{array}{l}\text { P value } \\
(0.05)\end{array}$ & Inference \\
\hline Between groups & 17.1124 & 7 & 2.4446 & 167.7274 & $9.19 \mathrm{e}^{-14}$ & Sig. \\
\hline Within groups & 0.2332 & 16 & 0.0146 & & & \\
\hline Total & 17.3456 & 23 & & & & \\
\hline \multicolumn{7}{|c|}{ ANOVA of effect of accelerated ageing on thickness swelling } \\
\hline & Sum of Squares & $\begin{array}{l}\text { Degrees of } \\
\text { freedom }\end{array}$ & Mean Square & F-statistics & $\begin{array}{l}\text { P value } \\
(0.05)\end{array}$ & Inference \\
\hline Between groups & 1.9822 & 7 & 0.2832 & 69.0656 & $9.16 \mathrm{e}^{-11}$ & Sig. \\
\hline Within groups & 0.0656 & 16 & 0.0041 & & & \\
\hline Total & 2.0478 & 23 & & & & \\
\hline
\end{tabular}

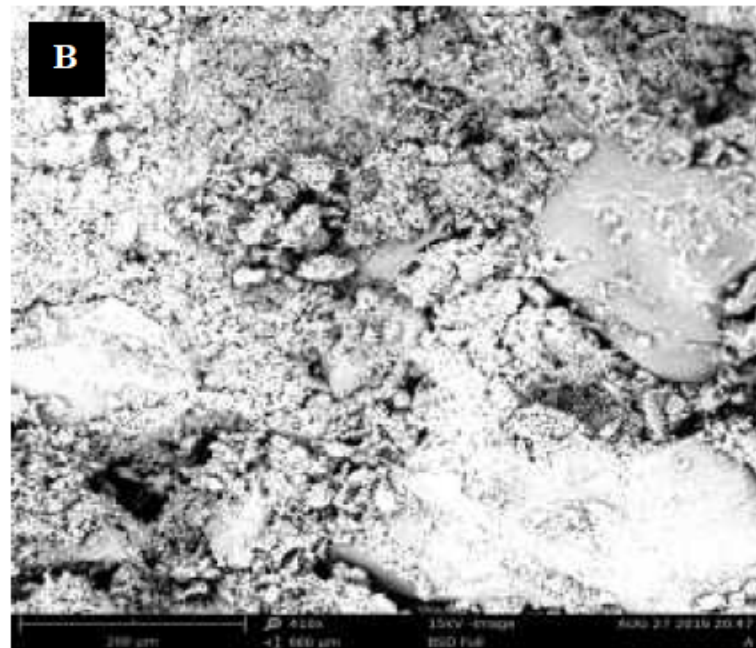

(a) Before ageing tests

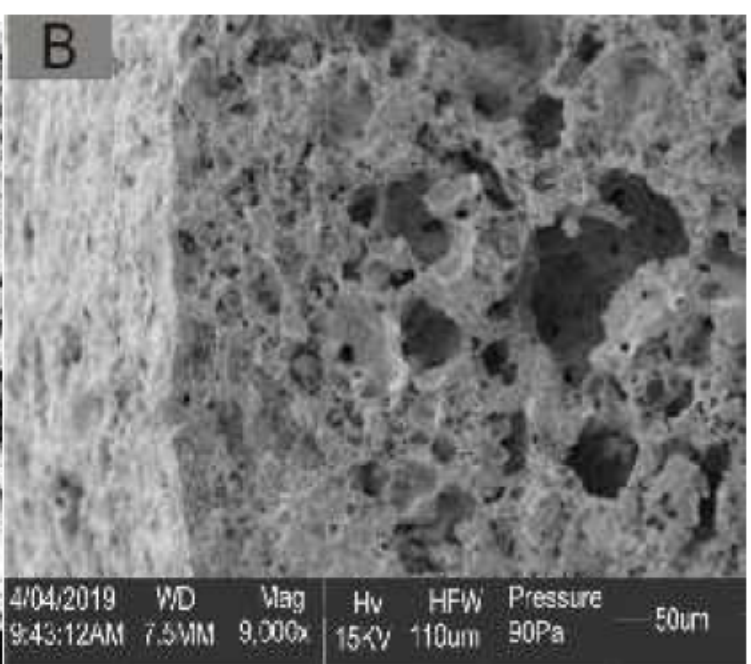

(b) After ageing tests

Figure 5: Sample B micrograph 


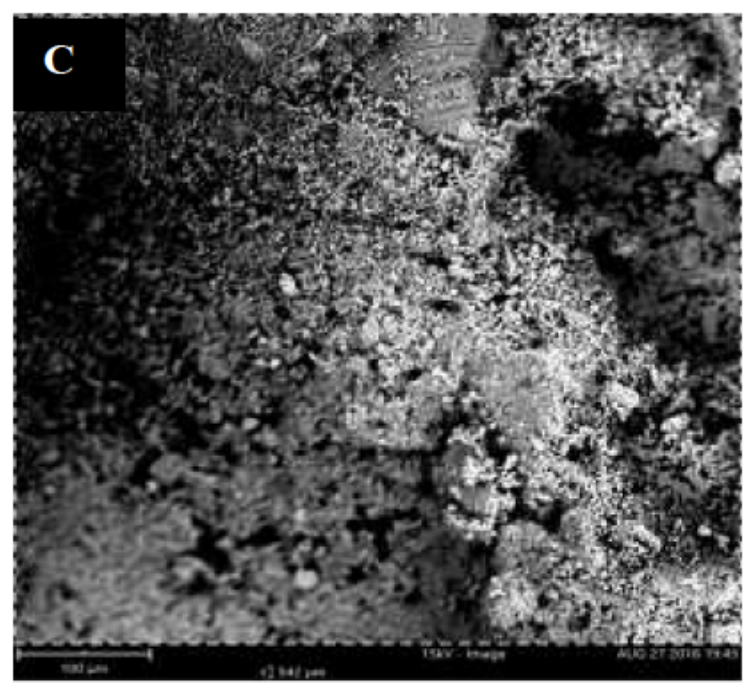

(a) Before ageing tests

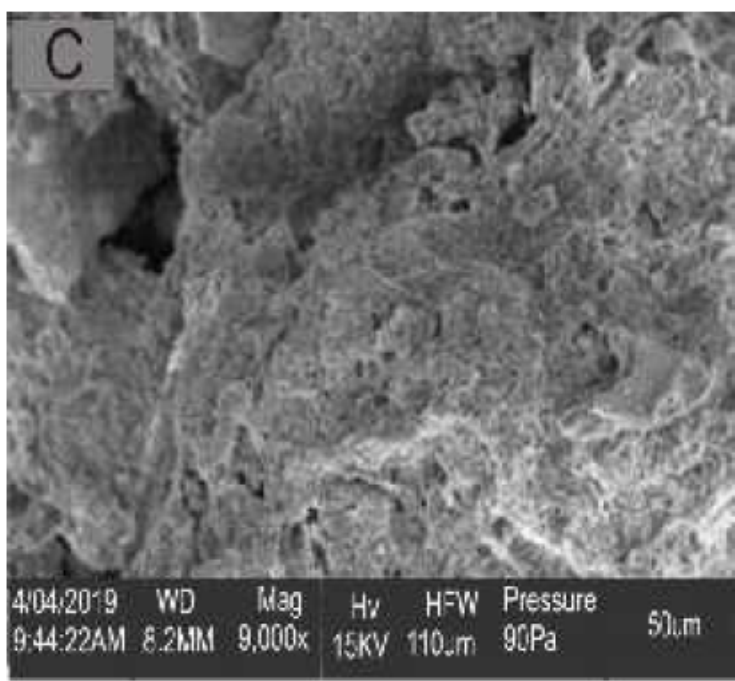

(b) After ageing tests

Figure 6: Sample C micrograph

absorption capability of the fibre-polymer-cement composites by improving the resistance to crack stresses and sustaining the ultimate strength while the ageing tests were on-going [25]. Figure 6 (I and ii) showed the discolouration of the polymer films after undergoing wetting and drying cycles. However, this discolouration did not affect its impact on the composite, as it could be observed that there was marginal increase in the size of the pores before and after ageing tests. The size of the pores would definitely influence the permeability of the composites which had been controlled to an extent. This was responsible for the improved dimensional stability observed in this study as against other studies involving unmodified fibre-cement composites as early stated. By connecting these observations with the MOR and MOE performance in the study, it could be stated that the influence of polymer active constituents with cement hydration products limited the development of voids which resulted into less degradation during the cycles.

\subsection{Fourier Transformer Infrared Spectroscopy (FTIR)}

The FTIR spectra of the composites are shown in Figure 7 while the vibrational frequencies of interest are displayed in Table 4. The spectra transmittances are in concordance with literatures which are characteristic of vegetable fibre cement composites [26, 27]. The frequency bands ranging from $3384-3520 \mathrm{~cm}^{-1}$ are denoted for O-H stretch- ing which are characteristics of the presence of lignin, cellulose and hemicellulose, these showed increases in intensity due to aging. Based on the findings of Zugernmaier [28], it was reported that the hydroxyl group in these constituents of the plant fibres increase the quantity of hydrogen bonds in their cell wall. During the wet/dry cycles, the moisture ingress causes breakage, which is followed by subsequent formation of new hydrogen bonds in combination with the molecules of water by the hydroxyl group leading to swelling in the cement composite. However, a higher energy is required to break down these bonds which is lacking during these cycles. Therefore for each applied cycle, there would be an increase in the hydrogen bonds (O-H group), hence an increase in intensity at these bands as noticed in the study. Spectra bands at 2206, 2360 and $2450 \mathrm{~cm}^{-1}$ are for of C-H (fibers) and -CH2- (polymers) groups. The transmittance peaks at 1676, 1726 and $1794 \mathrm{~cm}^{-1}$ depict the presence of carbonyl groups. These also showed an increase in intensity with aging because of absorption of polymers to the fibre surface during the cycles. Carbonyl groups are best known for their ability to bond with other functional groups [29]. This improved bonding is the mechanism responsible for some of the improved mechanical properties observed during the cycles leading to better and stronger material that is durable in outdoor environment. The polymer content of cement composite is possible to also have increased the carbonyl group formation during the wet/dry cycles because of chain scissions that usually occur during polymer degradation [30]. Other spectra bands of interest are 1068 - 
$1276 \mathrm{~cm}^{-1}$ characteristics of function groups of C-O (fibers) and C-C (polymers) and $770-808 \mathrm{~cm}^{-1}$ which are assigned for the tetrahedral $\mathrm{SiO}_{4}$ groups belonging to gels of $\mathrm{C}-\mathrm{S}-\mathrm{H}$ [31] and vibrational type of C- $\mathrm{CH}_{2}$ out of plane bending for the polymer derivatives after aging [32].

Table 4: Spectra of composite samples

\begin{tabular}{cccc}
\hline \multicolumn{3}{c}{ Vibration Frequencies } & Functional group \\
B & C & D & \\
\hline 3500 & 3520 & 3384 & $\mathrm{O}-\mathrm{H}$ stretching \\
2450 & 2360 & 2206 & $\mathrm{C}-\mathrm{H} /-\mathrm{CH}_{2}-$ vibration \\
1676 & 1794 & 1726 & $\mathrm{C}=\mathrm{H} / \mathrm{R}(\mathrm{C}=\mathrm{O}) \mathrm{OH}$ \\
1276 & 1218 & 1068 & $\mathrm{C}-\mathrm{O} / \mathrm{C}-\mathrm{C}$ \\
804 & 770 & 808 & $\mathrm{SiO}_{4} / \mathrm{RCH}=\mathrm{CH}_{2}$ \\
& & & bending \\
\hline
\end{tabular}

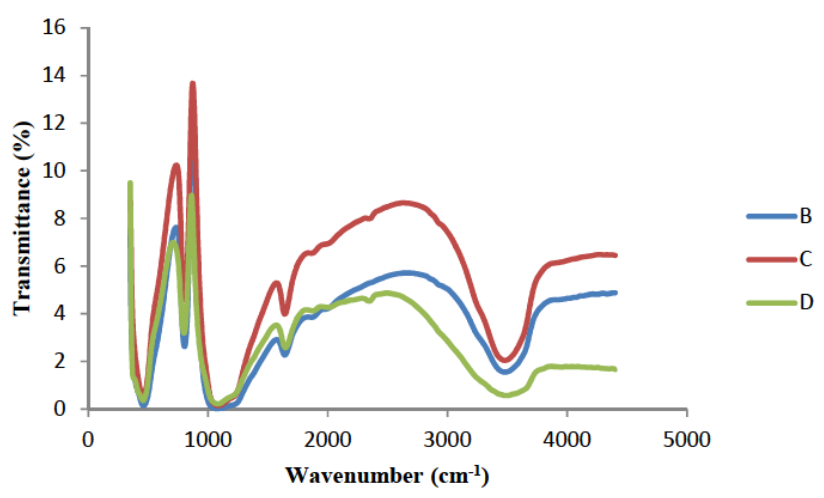

Figure 7: FTIR spectra of samples

\section{Conclusion}

On the strength of the observed results from the series of tests and analyses conducted, it could be deduced that significant improvement in MOR and MOE occurred in the modified cement matrix vegetable fibre reinforced composites during the wet/dry cycles. The inclusion of polymer admixtures improved the microstructural network of the composites by limiting the expansion of pores/voids during the cycles. It was also responsible for reduced interfacial de-bonding at the transition zone which could have led to less dense and compact matrix. This notable arrangement assisted in the reduction of the dimensional instability of the composites in comparison with literatures involving ageing of unmodified plant fibre-cement matrix.
FTIR analysis showed the distinct role the carbonyl group played in creating effective bonding with the functional groups from the polymer admixture. Its intensity was increased during the aging cycles because of chain scissions that usually occur during polymer weathering. However, further studies are expected to be conducted on the composite materials to evaluate their performance in outdoor environment when exposed to both ultraviolet rays from the sun and humidity variations for longer period.

Conflict of Interests: The authors declare no conflict of interest regarding the publication of this paper.

\section{References}

[1] Claramunt J, Ardanuy M, García-Hortal JA, Tolêdo Filho RD. The hornification of vegetable fibers to improve the durability of cement mortar composites. Cement and Concrete Composites. 2011 May 1;33(5):586-95.

[2] Ardanuy M, Claramunt J, Toledo Filho RD. Cellulosic fiber reinforced cement-based composites: A review of recent research. Construction and building materials. 2015 Mar 15;79:115-28.

[3] Sotiropoulou A, Gavela S, Nikoloutsopoulos N, Passa D, Papadakos $\mathrm{G}$. Experimental study of wood shaving addition in mortar and statistical modeling on selected effects. Journal of the Mechanical Behavior of Materials. 2017 Apr 25;26(1-2):55-63.

[4] Mohr BJ, Biernacki JJ, Kurtis KE. Microstructural and chemical effects of wet/dry cycling on pulp fiber-cement composites. Cement and Concrete Research. 2006 Jul 1;36(7):1240-51.

[5] Mokhothu TH, John MJ. Bio-based coatings for reducing water sorption in natural fibre reinforced composites. Scientific Reports. 2017 Oct 17;7(1):1-8.

[6] Wei J, Meyer C. Utilization of rice husk ash in green natural fiberreinforced cement composites: Mitigating degradation of sisal fiber. Cement and Concrete Research. 2016 Mar 1;81:94-111.

[7] Akinyemi BA, Dai C. Development of banana fibers and wood bottom ash modified cement mortars. Construction and Building Materials. 2020 Apr 30;241:118041.

[8] Swamy RN, Tanikawa S. An external surface coating to protect concrete and steel from aggressive environments. Materials and structures. 1993 Oct 1;26(8):465-78.

[9] Shakil UA, Hassan SB. Behavior and properties of tin slag polyester polymer concrete confined with FRP composites under compression. Journal of the Mechanical Behavior of Materials. 2020 Apr 15;29(1):44-56.

[10] Sergi G, Seneviratne AM, Maleki MT, Sadegzadeh M, Page CL. Control of reinforcement corrosion by surface treatment of concrete. Proceedings of the Institution of Civil Engineers-Structures and Buildings. 2000 Feb;140(1):85-100.

[11] Seneviratne AM, Sergi G, Page CL. Performance characteristics of surface coatings applied to concrete for control of reinforcement corrosion. Construction and Building Materials. 2000 Feb 28;14(1):55-9.

[12] Mumenya SW, Tait RB, Alexander MG. Mechanical behaviour of Textile Concrete under accelerated ageing conditions. Cement 
and Concrete Composites. 2010 Sep 1;32(8):580-8.

[13] Savastano Jr H, Warden PG, Coutts RS. Potential of alternative fibre cements as building materials for developing areas. Cement and Concrete composites. 2003 Aug 1;25(6):585-92.

[14] Bentur A, Akers SA. The microstructure and ageing of cellulose fibre reinforced cement composites cured in a normal environment. International Journal of Cement Composites and Lightweight Concrete. 1989 May 1;11(2):99-109.

[15] Akinyemi B, Omoniyi T. Properties of latex polymer modified mortars reinforced with waste bamboo fibers from construction waste. Buildings. $2018 \mathrm{Nov}$;8(11):149.

[16] Akinyemi BA, Omoniyi TE. Effect of moisture on thermal properties of acrylic polymer modified mortar reinforced with alkali treated bamboo fibres. Journal of the Indian Academy of Wood Science. 2018 Jun 1;15(1):45-51.

[17] EN 494:2004/A1:2005 - Fibre-cement profiled sheets and fittings - Product specification and test methods

[18] Tonoli GH, Rodrigues Filho UP, Savastano Jr H, Bras J, Belgacem MN, Lahr FR. Cellulose modified fibres in cement based composites. Composites Part A: Applied Science and Manufacturing. 2009 Dec 1;40(12):2046-53.

[19] Tonoli GH, Santos SF, Teixeira RS, Pereira-da-Silva MA, Lahr FR, Silva FP, Savastano Jr H. Effects of eucalyptus pulp refining on the performance and durability of fibre-cement composites. Journal of Tropical Forest Science. 2013 Jul 1:400-9.

[20] Soroushian P, Marikunte S, Won JP. Wood fiber reinforced cement composites under wetting-drying and freezing-thawing cycles. Journal of materials in civil engineering. 1994 Nov;6(4):595-611.

[21] Diamanti MV, Brenna AN, Bolzoni FA, Berra MA, Pastore T, Ormellese MA. Effect of polymer modified cementitious coatings on water and chloride permeability in concrete. Construction and Building Materials. 2013 Dec 1;49:720-8.

[22] Tonoli GH, Joaquim AP, Arsène MA, Bilba K, Savastano Jr H. Performance and durability of cement based composites reinforced with refined sisal pulp. Materials and Manufacturing Processes. 2007 Feb 2;22(2):149-56.
[23] Ferraz PF, Avelino MD, Carvalho VR, da Silva IM, de Lima Domingos AL, Mendes RF, de Oliveira Castro J, Conti L, Rossi G. Physical Properties of Cement Panels Reinforced with Lignocellulosic Materials. InInternational Mid-Term Conference of the Italian Association of Agricultural Engineering 2019 Sep 12 (pp. 231-237). Springer, Cham.

[24] Booya E, Gorospe K, Das S. Performance of engineered pulp fibre reinforced composites subjected to weathering conditions. Journal of Building Engineering. 2019 Sep 1;25:100816.

[25] Al Menhosh A, Wang Y, Wang Y. The mechanical properties of the concrete using metakaolin additive and polymer admixture. Journal of Engineering. 2016 Jan 1;2016.

[26] Barreto AC, Rosa DS, Fechine PB, Mazzetto SE. Properties of sisal fibers treated by alkali solution and their application into cardanol-based biocomposites. Composites Part A: Applied Science and Manufacturing. 2011 May 1;42(5):492-500.

[27] Ferreira SR, de Andrade Silva F, Lima PR, Toledo Filho RD. Effect of hornification on the structure, tensile behavior and fiber matrix bond of sisal, jute and curauá fiber cement based composite systems. Construction and Building Materials. 2017 May 15;139:551-61.

[28] Zugenmaier P. Crystalline cellulose and derivatives: characterization and structures. Springer Science \& Business Media; 2008 Jan 12.

[29] Derkacheva O. Studying the structure of native, residual and dissolved lignins by FTIR spectroscopy method. In Proceedings of first international workshop on physicochemical properties of lignins 2005 (pp. 255-257).

[30] Wypych G. Handbook of material weathering. Elsevier; 2018 Feb 22.

[31] Claramunt J, Fernández-Carrasco LJ, Ventura H, Ardanuy M. Natural fiber nonwoven reinforced cement composites as sustainable materials for building envelopes. Construction and Building Materials. 2016 Jul 15;115:230-9.

[32] Pages P, Carrasco F, Surina J, Colom X. FTIR and DSC study of HDPE structural changes and mechanical properties variation when exposed to weathering aging during Canadian winter. Journal of Applied Polymer Science. 1996 Apr 11;60(2):153-9. 